\title{
Analysis of Tactical Behaviours in Small-Sided Soccer Games: Compara- tive Study Between Goalposts of Society Soccer and Futsal
}

\author{
I. Costa ${ }^{1,3}$, J. Garganta ${ }^{3,4, *}$, P. Greco ${ }^{2}$, I. Mesquita ${ }^{3,4}$, B. Silva ${ }^{3}$, E. Müller ${ }^{3}$, D. Castelão ${ }^{3}$, \\ A. Rebelo ${ }^{3,4}$ and A. Seabra ${ }^{3,4}$ \\ ${ }^{1}$ University Center of Belo Horizonte, UNI-BH, Belo Horizonte, MG, Brazil \\ ${ }^{2}$ Federal University of Minas Gerais, UFMG, Belo Horizonte, MG, Brazil \\ ${ }^{3}$ Faculty of Sport, University of Porto, FADEUP, Porto, Portugal \\ ${ }^{4}$ Center of Research, Training, Intervention and Innovation in Sport, CIFI2D, FADEUP, Porto, Portugal
}

\begin{abstract}
The purpose of this study was to compare the tactical behaviours performed by youth soccer players in a smallsided, according to different goalposts of Society Soccer $(6 \mathrm{~m} \times 2 \mathrm{~m})$ and Futsal $(3 \mathrm{~m} \times 2 \mathrm{~m})$. The players performed 146 tactical actions in the field with goalposts of Soccer Society and 536 in the field with goalposts of Futsal. Descriptive analysis and chi-square test $(\mathrm{p} \leq 0.05)$ were carried out to characterize the sample and check the association. The Kappa of Cohen coefficient was used to check inter- and intra-observers reliability. It was not found statistical differences for tactical principles performed by players in the field with goalposts of Futsal and with goalposts of Society Soccer. It is possible to conclude that there was an independent relationship between tactical actions performed by players in the field with goalposts of Futsal and with goalposts of Society Soccer $(p<0.05)$. Thus, the "GK3-3GK" test can be applied to evaluate tactical behaviours performed by soccer players in both situations.
\end{abstract}

Keywords: Soccer, tactical behaviour, goalpost of society soccer, goalpost of futsal.

\section{INTRODUCTION}

Soccer, Futsal and Society Soccer present goalposts with different dimensions as stipulated by the official rules of each sport. The format and dimensions of the goalposts influence the way the players see the goal. Thus, different goalposts could determine the tactical patterns of the players, particularly relating to the possibilities of attacking/ defending on the field, the adoption of a style of play (direct or indirect), and the perception of the opening/closing angle of the shots [1].

Logistical problems appear to be common in the training of youth teams, since the coach has to plan the training sessions according to the space and the equipment available. From these difficulties, the goalposts and the area of the field available for the practice are variables that can be adjusted by the coach to achieve the objectives of the training session. Therefore, it is important to analyse the implications that different circumstances in the training can have on the behaviour of the players, particularly in the tactical principles performed, both offensively and defensively.

This study aims to compare the tactical behaviours performed by youth soccer players in a small-sided game using different goalposts of Society Soccer $(6 \mathrm{~m} \times 2 \mathrm{~m})$ and Futsal $(3 \mathrm{~m} \times 2 \mathrm{~m})$.

*Address correspondence to this author at the Faculty of Sport, Porto University, Porto Portugal; Tel: +351 225074771 ;

E-mail: jgargant@fade.up.pt

\section{MATERIAL AND METHODS}

\section{Participants and Sample}

In the present study, 16 Under-13s players have been analyzed. The players performed 146 tactical actions in the field with goalposts of Soccer Society and 536 in the field with goalposts of Futsal. It was not analysed the data from: throw-ins, free kicks and situations where the player did not move.

\section{Applied Method}

Players performed a 4 minute small-sided game $(3 v s .3$ with goalkeepers). The "GK3-3GK" Test is designed in a field of 36 meters length and 27 meters width. With exception of the offside rule, all official soccer rules were applied. The test aimed to evaluate the tactic actions performed by players (with and without the ball) attending on ten fundamental tactical principles of the Soccer game. Additionally, the test considered place of action and the action outcome.

\section{Procedures}

The data for our study was attained in two Portuguese clubs with directors' permission. Prior to the test, a brief explanation of the objectives was given to the players. The teams were formed randomly and the players were wearing numbered vests in order to facilitate their identification. A thirty-second period had been granted to familiarize them with the test and after which the game began. 


\section{Materials}

The games had been recorded with the digital camera PANASONIC NV - DS35EG. The digital videos were transferred to a laptop via cable and converted into "avi" files. Softwares Utilius VS and Soccer Analyser were used for data processing.

\section{Statistical Analysis}

Statistical procedures were done using SPSS software for Windows ${ }^{\circledR}$, version 17.0. Descriptive analyses (frequency, percentage and percentage variation) were carried out to characterize the sample. The normal distribution of the data was verified by the test of Kolmogorov-Smirnov and homogeneity of variances was assured by test of Levene. The chisquare $\left({ }^{2} \times\right)$ with a significance level of $p<0.05$ was used to check the association between tactical principles performed by the players when it was used different kinds of goalposts. The Kappa of Cohen coefficient was used to check inter- and intra-observers reliability.

\section{Reliability Analysis}

To determine the reliability of the observation, the testretest method was used to obtain the stability-reliability coefficient. Three observers were trained to review 242 tactical actions that represent $35.50 \%$ of the sample. This percent

Table 1. Principles, Place of Action and Action Outcomes of the“GK3-3GK" Test

\begin{tabular}{|c|c|c|c|c|c|}
\hline \multirow[b]{2}{*}{ Game Principles } & \multicolumn{2}{|c|}{ Goalpost of Society Soccer } & \multicolumn{2}{|c|}{ Goalpost of Futsal } & \multirow[b]{2}{*}{$\% \mathbf{V}^{*}$} \\
\hline & $\mathbf{N}$ & $\%$ & $\mathbf{N}$ & $\%$ & \\
\hline \multicolumn{6}{|l|}{ - Offensive Principles } \\
\hline Penetration & 10 & 6,8 & 27 & 5,0 & $-26,5$ \\
\hline Offensive Coverage & 15 & 10,3 & 53 & 9,9 & $-3,8$ \\
\hline Depth Mobility & 6 & 4,1 & 23 & 4,3 & 4,4 \\
\hline Offensive Unity & 11 & 7,5 & 57 & 10,6 & 41,1 \\
\hline \multicolumn{6}{|l|}{ - Defensive Principles } \\
\hline Delay & 21 & 14,4 & 48 & 9,0 & $-37,7$ \\
\hline Defensive Unity & 43 & 29,5 & 147 & 27,4 & $-6,9$ \\
\hline Total & 146 & 100 & 536 & 100 & 0 \\
\hline \multicolumn{6}{|l|}{ Place of Action } \\
\hline \multicolumn{6}{|l|}{ - Offensive Midfield } \\
\hline Offensive actions & 26 & 17,8 & 123 & 22,9 & 28,9 \\
\hline Defensive actions & 42 & 28,8 & 108 & 20,1 & $-30,0$ \\
\hline \multicolumn{6}{|l|}{ - Defensive Midfield } \\
\hline Offensive actions & 35 & 24,0 & 129 & 24,1 & 0,4 \\
\hline Loss of ball possession & 19 & 13,0 & 57 & 10,6 & $-18,3$ \\
\hline \multicolumn{6}{|l|}{ - Defensive phase } \\
\hline Regain the ball possession & 24 & 16,4 & 56 & 10,4 & $-36,4$ \\
\hline Ball possession of the opponent & 55 & 37,7 & 212 & 39,6 & 5,0 \\
\hline Shot at goal of the opponent & 6 & 4,1 & 16 & 3,0 & $-27,4$ \\
\hline
\end{tabular}

*Calculated from the relationship between the goalpost of Society Soccer to the goalpost of Futsal. 
is above the value of reference (10\%), recommended by the literature [2]. The results reveals an inter-observers agreement coefficient of 0.94 (standard-deviation $=0.01$ ), 0.89 (standard-deviation $=0.02$ ) and 0.88 (standard-deviation $=0.02$ ) and intra-observers agreement coefficient of 0.93 $($ standard deviation $=0.01), 0.88($ standard-deviation $=0.02)$ and 0.90 (standard-deviation $=0.02$ ). These values are above the conventional level of acceptance (0.61) [3].

\section{RESULTS AND DISCUSSION}

Table 1 presents the information of the "GK3-3GK" Test showing the frequency and the percentage of the tactical principles, place where they were performed and their outcomes. The percentages of the goalposts are also presented.

Analyzing the tactical offensive actions, there was a higher percentage variation for tactical principles "Width and Length" and "Offensive Unity." Probably, it indicates that the players tried to increase width and depth when using Futsal goalposts. This increase tended to be more effective in the offensive midfield, since the players performed more offensive actions in the offensive field when using Futsal goalposts comparing to when playing with goalposts of Society Soccer.

Moreover, it should be noted a high percentage variation of "Penetration", which indicates that the players choose to perform more this tactical principle, thus being more objective in the offensive phase and shooting more on goal, when using smaller goalposts.

In the tactical defensive actions, there was a variation of $37.7 \%$ for the "Delay" tactical principle, showing that the players performed more actions of this principle when using goalposts of Society Soccer. This could be a defensive response to the offensive actions of "Penetration" and also an attempt to reduce the space to play of the opponent team, once the size of the goalpost of Society Soccer are bigger than the goalposts of Futsal allowing the opponent players to shot more times on goal, as it is shown in Table 1. This attempt to reduce the area of game can be related to the place where the actions are performed, as the players presented more defensive actions in the offensive field when it was used the goalpost of Society Soccer. Once the players performed more actions of "Delay" in the field with goalposts of Society Soccer, it is plausible that this behaviour may have direct influences on the outcomes, because in the field with goalposts of Society Soccer there is more recovery of ball possession. The players did not perform the tactical action of "Defensive Coverage" and it can be speculated that it is justified by the reduced size of the field. Once the field is small, it can intimidate the players to support the one that is performing "Delay" principle.

There is a greater percentage of variation for the principle of "Concentration", showing that the players perform this kind of principle more often in the field with goalposts of Futsal, even knowing that this kind of goalposts offers lower risk to the opponent score. That type of behaviour can allow the opponent player to keep more possession of the ball as it was seen in the outcomes.

There was an independent relationship between tactical actions performed by players in the field with goalposts of Futsal and with goalposts of Society Soccer $(\mathrm{p}<0.05)$.

Once the goalposts used not cause significant changes in the tactical patterns of the players, it is possible to conclude that the "GK3-3GK" Test can be applied to evaluate tactical behaviours performed by soccer players in both situations, independently the size of the goalposts used.

\section{ACKNOWLEDGEMENT}

Supported by the Programme AlBan, the European Union Programme of High Level Scholarships for Latin America, scholarship n ${ }^{\circ}$ E07D400279BR".

\section{REFERENCES}

[1] Garganta J. Competências no ensino e treino de jovens futebolistas. Lecturas: EF y Deportes. Revista Digital 2002; 8(45). Available at: www.efdeportes.com

[2] Tabachnick B, Fidell L. Using multivariate statistics. $2^{\text {a }}$ Ed. New York: Harper \& Row Publishers 1989.

[3] Landis JR, Koch GC. The measurement of observer agreement for categorical data. Biometrics 1977; 33: 1089-91. 